\title{
Wound healing effect of an Astragalus membranaceus polysaccharide and its mechanism
}

\author{
BINGJIANG ZHAO ${ }^{1,2}$, XUANFEN ZHANG ${ }^{1}$, WEI HAN ${ }^{3}$, JU CHENG $^{2}$ and YONGHONG QIN ${ }^{1}$ \\ ${ }^{1}$ Department of Plastic Surgery, The Second Hospital of Lanzhou University; ${ }^{2}$ Institute of Operative Surgery, \\ School of Basic Medical Sciences, Lanzhou University; ${ }^{3}$ Department of Thoracic Surgery, \\ The Second Hospital of Lanzhou University, Lanzhou, Gansu 730030, P.R. China
}

Received February 9, 2016; Accepted January 18, 2017

DOI: $10.3892 / \mathrm{mmr} .2017 .6488$

\begin{abstract}
In the present study, a novel polysaccharide, APS2-1, was isolated and purified from Astragalus membranaceus using DEAE-cellulose and Sephadex G-100 chromatography. The effect of APS2-1 on the promotion of wound healing was evaluated and its preliminary mechanism was investigated. In vitro experiments showed that APS2-1 was able to promote human skin fibroblast (HSF) propagation and accelerate cell cycle progression. For further examination, a scalded mice model was used to verify the effect of APS2-1 and investigate its mechanism of action. The analysis of biochemical parameters, including cyclin D1, inhibitor of nuclear factor $\kappa \mathrm{B} \alpha(\mathrm{I} \kappa \mathrm{B} \alpha)$, transforming growth factor (TGF)- $\beta 1$, basic fibroblast growth factor (bFGF) and epidermal growth factor (EGF) showed that APS2-1 inhibited the increase in cyclin $\mathrm{D} 1$ and $\mathrm{I} \kappa \mathrm{B} \alpha$, and promoted the expression of TGF- $\beta 1$, bFGF and EGF, which was further confirmed by histopathological observation. These results suggested that APS2-1 possessed high potential in wound healing and its mechanism was associated with inhibiting inflammation, accelerating cell cycle and promoting the secretion of repair factors.
\end{abstract}

\section{Introduction}

Astragalus, known as Huang Qi in China, comprises the dry roots of Astragalus membranaceus (Hsiao) Bge or Astragalus membranaceus (Fisch) Bge. It has been used as an important component of herbal prescriptions to reduce swelling, drain pus and eradicate toxins for thousands of years (1). Several biological active ingredients have been obtained from Astragalus membranaceus, including polysaccharides, saponins, flavonoids, amino acids and trace

Correspondence to: Dr Xuanfen Zhang, Department of Plastic Surgery, The Second Hospital of Lanzhou University, 82 Cuiyingmen, Chengguan, Lanzhou, Gansu 730030, P.R. China E-mail: sefonzhang@126.com

Key words: Astragalus membranaceus, polysaccharide, wound healing elements. However, modern pharmacological investigations have demonstrated that the primary pharmacological ingredients of Astragalus membranaceus in wound healing are polysaccharides and saponins, which have effects on the improvement of immune function and the stimulation of cell physiology metabolism (2). Yang et al (3) reported that Astragalus polysaccharide (APS) has an effect on diabetic skin wounds. Therefore, APS is considered to be important in promoting wound healing.

To improve current understanding of APS on wound healing properties and the possible mechanisms, the present study purified a fraction, APS2-1, from a type of commercial Astragali. Following purification, the effects of APS2-1 on the proliferation, migration and cell cycle progression of human fibroblasts were examined. In addition, the mRNA and protein expression levels of cyclin D1 and I $\mathrm{B} \alpha$ in the presence of APS2-1 were evaluated. The secretion of transforming growth factor (TGF)- $\beta 1$, basic fibroblast factor (bFGF), and epidermal growth factor (EGF) were also measured. Ultimately, the wound healing properties of APS2-1 were evaluated in a scalded mouse model. The aims of the present study were to provide valuable data for evaluating the wound healing effect of APS2-1, in order to effectively and appropriately exploit APS2-1 for treating wounds in the future.

\section{Materials and methods}

Materials and chemicals. The Astragalus membranaceus roots were purchased from Guangyi Chinese Herbal Cultivation Co., Ltd (Fengzhen, China). DEAE-cellulose 52 and Sephadex G-100 were purchased from Sigma-Aldrich; Merck Millipore (Darmstadt, Germany) and Pharmacia; GE Healthcare Life Sciences (Uppsala, Sweden), respectively. 3-(4,5)-dimethylthiazol-2-yl)-2,5-diphenyltetrazolium bromide (MTT) and dimethylsulfoxide (DMSO) were purchased from Sigma-Aldrich; Merck Millipore. DMEM, streptomycin and penicillin were obtained from Hyclone; GE Healthcare Life Sciences (Logan, UT, USA). ELISA kits for TGF- $\beta 1$, bFGF, EGF and cyclin D1 were purchased from Shanghai Honsun Biological Co., Ltd. (Shanghai China). TRIzol reagent and SYBR Green I detection reagents were purchased from Bio-Rad Laboratories, Inc., (Hercules, CA, USA). Bovine serum albumin (BSA) was purchased from Sangon Biotech 
Co., Ltd. (Shanghai, China). All primary antibodies were obtained from Cell Signaling Technology, Inc. (Danvers, MA, USA). The secondary antibody was purchased from Wuhan Boster Biological Technology, Ltd. (Wuhan, China). All other reagents were of analytical grade and purchased from local chemical suppliers in China.

Extraction and purification of APS. The Astragalus membranaceus roots were dried at $50^{\circ} \mathrm{C}$, broken and passed through a 100 -eye mesh, followed by defatting with $95 \%$ ethanol at room temperature for $48 \mathrm{~h}$ to remove the majority of the polyphenols, pigments and monosaccharides (performed three times) (4). The defatted powder $(100 \mathrm{~g})$ was then extracted with distilled water $(\mathrm{m}: \mathrm{v}=1: 5)$ at $80^{\circ} \mathrm{C}$ for $2 \mathrm{~h}$, and centrifuged at $13,400 \mathrm{x} \mathrm{g}$ for $10 \mathrm{~min}$ at room temperature. Following centrifugation, the supernatant was concentrated in a rotary evaporator to $100 \mathrm{ml}$ and then precipitated by adding four times the volume of anhydrous ethanol for $12 \mathrm{~h}$ at $4^{\circ} \mathrm{C}$. The precipitate was dissolved in $200 \mathrm{ml}$ distilled water and deproteinized using the Sevag method (5), producing the crude APS solution. The crude APS solution was dialyzed against double-distilled water for 3 days and lyophilized to crude APS.

The crude APS $(50 \mathrm{mg})$ was dissolved in $1 \mathrm{ml}$ distilled water, and fractionated on a DEAE-cellulose anion-exchange column $(1.6 \times 25.0 \mathrm{~cm})$ with double distilled water and $0.1 \mathrm{M}$ $\mathrm{NaCl}$ at a flow rate of $2 \mathrm{ml} / \mathrm{min}$, producing the two fractions of APS-1 and APS-2, respectively. APS-2 was further purified on a Sephadex G-100 column $(1.6 \times 50.0 \mathrm{~cm})$ with double distilled water at a flow rate of $1.00 \mathrm{ml} / \mathrm{min}$, producing a homogeneous fraction, APS2-1.

Infared (IR) and ultraviolet (UV) spectroscopy. APS2-1 $(3.0 \mathrm{mg}$ ) was ground with $\mathrm{KBr}$ and pressed into a $1 \mathrm{~mm}$ pellet. The IR spectrum between 4,000 and $400 \mathrm{~cm}^{-1}$ was recorded on a Perkin-Elmer spectrometer. For the UV spectrum, the aqueous solution of APS2-1 at $1.0 \mathrm{mg} / \mathrm{ml}$ was scanned with wavelengths between 190 and $400 \mathrm{~nm}$ on a UV-vis spectrophotometer.

\section{In vitro wound healing assay}

Analysis of cell viability. Human skin fibroblast cells (CCC-HSF-1; HSF) were seeded at a density of 3,000 cells per well in a 96-well plate containing DMEM with $10 \%$ (v/v) FBS. The cells were then incubated in 1,5 and $25 \mathrm{mg} / \mathrm{l}$ concentrations of APS2-1 for $48 \mathrm{~h}$ at $37^{\circ} \mathrm{C}$. An additional culture of cells in DMEM in the absence of APS2-1 was used as control.

At the end of culture, $30 \mu \mathrm{l}$ MTT-PBS solution $(5 \mathrm{mg} / \mathrm{ml})$ was added directly into each well. The plates were further incubated for $4 \mathrm{~h}$ at $37^{\circ} \mathrm{C}$, followed by the addition of $100 \mu \mathrm{l}$ DMSO to each well. The absorbance was recorded at $540 \mathrm{~nm}$ and measured using a spectrophotometer (6).

Analysis of CCC-HSF-1 migration and cell cycle. The effect of APS2-1 on CCC-HSF-1 migration was measured using a Transwell migration assay $(8.0 \mu \mathrm{m}$ pore size; Corning Incorporated, Corning, NY, USA) according to the manufacturer's protocol. In brief, $1 \times 10^{4}$ CCC-HSF-1 cells were seeded in the upper chamber of 24-well plates and cultured in serum-free DMEM supplemented with $0.5 \%$ of BSA. APS2-1 was added directly to the cell suspension at a final concentration of $25 \mathrm{mg} / \mathrm{l}$ for 24,48 and $72 \mathrm{~h}$. Cells cultured in the same medium without APS2-1 were used as the normal control., As a chemoattractant, 10\% FBS was added into the lower well of the culture plate. The cell suspension was left in the inside of each insert to migrate at $37^{\circ} \mathrm{C}$. After $24 \mathrm{~h}$, the migrated cells on the bottom side of the insert were fixed with paraformaldehyde and stained with hematoxylin, following which images were captured. The cells were counted from eight randomly-selected regions per well using a Nikon E200 ${ }^{\circledR}$ photomicroscope (Nikon Corporation, Tokyo, Japan), equipped with the Moticam $2300^{\circledR}$ image capture system (version 3.2; Motic Deutschland GmbH, Wetzlar, Germany). The data were from three independent experiments performed in duplicate (7).

In order to investigate the effect of APS2-1 on HSF cell proliferation, the effect of APS2-1 on progression of the cell cycle was evaluated. The HSF cells, which were in the exponential phase of growth, were treated with APS2-1 (final concentration, $25 \mathrm{mg} / \mathrm{l}$ ) for $24 \mathrm{~h}$ at $3 \times 10^{4}$ cells/well. Cells cultured in DMEM in the absence of APS 2-1 were used as the normal control. Subsequently, the cell supernatants were collected and the cells were stained with propidium iodide. Following FACSCalibur flow cytometry (BD Biosciences Franklin Lakes, NJ, USA), Mod-Fit LT ${ }^{\mathrm{TM}}$ version 3.2 analytic software (Verity Software House, Topsham, ME, USA) was used to determine the DNA content of cells (8).

Reverse transcription-quantitative polymerase chain reaction $(R T-q P C R)$ analysis and western blot analysis. Following incubation of the HSF cells $\left(1 \times 10^{6}\right.$ cells/well in a 96-well plate) with APS2-1 for $48 \mathrm{~h}$ at $37^{\circ} \mathrm{C}$ in a humidified incubator with $5 \% \mathrm{CO}_{2}$, the cells were collected to prepare total RNA and total protein. Total RNA was extracted from the HSF cells, which had been cultured with APS2-1 for $48 \mathrm{~h}$, using TRIzol reagent (Bio-Rad Laboratories, Inc.). The concentration of extracted RNA was determined using a UV spectrophotometer. cDNA was synthesized from $500 \mathrm{ng}$ total RNA using PrimeScript ${ }^{\mathrm{TM}}$ RT reagent (Takara Bio, Inc., Otsu, Japan). The primers used for qPCR were as follows: Cyclin D1, forward 5'-GAGACCATC CCCCTGACGGC-3' and reverse 3'-TCTTCCTCCTCCTCG GCGGC-5'; $\beta$-actin, forward 5'-CTGTCCCTGTATGCCTCT G-3' and reverse 5'-ATGTCACGCACGATTTCC-3'. The reactions (containing $10 \mu \mathrm{l}$ SYBR Green Master Mix, $1 \mu \mathrm{l}$ primers, $1 \mu \mathrm{l}$ cDNA sample liquid, and $8 \mu \mathrm{l}$ diethyl pyrocarbonate) were performed using a SYBR PrimeScript RT-PCR kit (Takara Bio, Inc.) with an ABI 7500 sequence detection system (Applied Biosystems; Thermo Fisher Scientific, Inc.). The amplifying conditions were as follows: 12 min predenaturation at $95^{\circ} \mathrm{C}$, and then 30 cycles of $94^{\circ} \mathrm{C}$ for $20 \mathrm{sec}, 60^{\circ} \mathrm{C}$ for $30 \mathrm{sec}, 72^{\circ} \mathrm{C}$ for $30 \mathrm{sec}$. Each experiment was performed with three biological replicates. As an internal control, levels of $\beta$-actin were quantified in parallel with the target genes. Normalization and fold changes were calculated using the $2^{-\Delta \Delta \mathrm{Ca}}$ method (9).

The proteins in the nucleus and cytoplasm were extracted using Sangon nuclear and cytoplasmic extraction reagents, respectively, according to the manufacturer's protocol (Sangon Biotech Co., Ltd.), and then quantified using a bicinchoninic acid Protein Assay kit (Pierce; Thermo Fisher Scientific, Inc.). The nuclear and cytoplasmic extracts $(40 \mu \mathrm{g})$ were separated on a $10 \%$ polyacrylamide gel and transferred onto 
a polyvinylidene difluoride membrane. The blot was subsequently blocked with 5\% non-fat milk in TBST for $2 \mathrm{~h}$ at room temperature, and then incubated with the following primary antibodies for $12 \mathrm{~h}$ at $4^{\circ} \mathrm{C}$ : Anti-nuclear factor $(\mathrm{NF})-\kappa \mathrm{B}$ p65

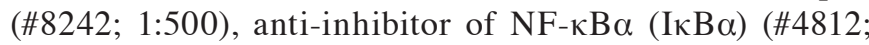
1:1000), anti-cyclin D1 (\#2978; 1:1,000), anti- $\beta$-actin (\#4970; 1:1,000) and anti-histone H3 (\#5748; 1:500), all purchased from Cell Signaling Technology, Inc. This was followed by incubation with goat anti-rabbit IgG-horseradish peroxidase (\#BA1054; 1:200, Wuhan Boster Biological Technology, Ltd.) for $2 \mathrm{~h}$ at room temperature. The immunoreactive bands were visualized using ECL western blot detection reagents (Thermo Fisher Scientific, Inc.). The optical densities of bands were measured and quantified using an image analysis system (ImageQuant LAS4000mini; GE Healthcare Life Sciences).

\section{In vivo wound healing assay}

Animal experiments. Specific pathogen-free male C57BL/6 mice (age, 10-11 weeks; weight, 20 2 g) used in the wound healing assessment were provided by Shanghai SLRC Laboratory Animal Co., Ltd. (SCXK2003-0003; Shanghai, China). All mice were acclimatized under conditions of $22-25^{\circ} \mathrm{C}$ and a 12 -h light-dark cycle, with free access to common rod-like diets and water. Following acclimation, the mice were randomized into three groups (13 mice per group). Following hair removal from the dorsal surface, the mice were anesthetized with sodium pentobarbital $(0.5 \mathrm{mg} / \mathrm{g})$, and a $10-\mathrm{mm}$ full-thickness excisional skin wound was made on the back of each mouse. Each wound was treated with $0.5 \mathrm{~g}$ ointment (APS2-1: Vaseline/SDS/ $\mathrm{H}_{2} \mathrm{O}=2: 60: 2: 65$ ) as the experimental group, $\mathrm{PBS}$ : Vaseline/SDS/ $\mathrm{H}_{2} \mathrm{O}=2: 60: 2: 65$ as the control group and Jingwanhong ointment (Tianjin Darentang Jingwanhong Pharmaceutical Co., Ltd, Tianjin, China) as the positive control for 3 weeks and dressed with fresh gauze. All mice were housed individually.

Histopathological examination. Images of the wounds were captured with a 10-megapixel digital camera (Sony Corporation, Tokyo, Japan) at 7, 14 and 21 days, and an image analyzer (Image-Pro Plus 6.0; Media Cybernetics, Inc., Rockville, MD, USA) was used to obtain wound-size measurements. At the end of 7,14 and 21 days, wound healing was quantified by calculating the remaining wound area for each group. The percentage of wound closure was calculated as follows: wound closure $(\%)=($ area of original wound-area of actual wound)/area of original wound $\times 100$. To assess the wound histologically, mice at day 14 were sacrificed by cervical dislocation for histological assessment. The harvested wound areas, including a border of normal tissue, were immediately fixed in $10 \%$ neutral-buffered formalin. The specimens were embedded in paraffin, sectioned into $5 \mu \mathrm{m}$ slices, and stained with hematoxylin and eosin to determine the quality of wound healing using a Nikon E200 ${ }^{\circledR}$ photomicroscope equipped with the Moticam $2300^{\circledR}$ image capture system (10). The scalded tissue samples at 7 days were collected and maintained at $-80^{\circ} \mathrm{C}$ for further evaluation.

Biochemical analysis. The scalded tissue samples at 7 days were prepared through homogenization in PBS, and the supernatants were collected by centrifugation of the tissue homogenate at
$9,300 \times \mathrm{g}$ under $4^{\circ} \mathrm{C}$ for $10 \mathrm{~min}$. The levels of TGF- $\beta 1, \mathrm{bFGF}$, EGF and cyclin D1 in the scalded tissue were determined using commercial kits according to the manufacturer protocols.

Statistical analysis. All data are expressed as the mean \pm standard deviation and were analyzed using one-way analysis of variance followed by a LSD-T range test using Graphpad Prism 5 Software (GraphPad Software, Inc., San Diego, CA, USA). $\mathrm{P}<0.05$ was considered to indicate a statistically significant difference.

\section{Results}

Purification and spectra analysis of APS2-1. The crude polysaccharide isolated from the root of Astragalus by a series of experimental procedures, including ethanol infusion, water extraction, deproteination, dialysis, ethanol precipitation, and lyophilization, was termed APS. Following purification via DEAE-cellulose 52 ion-exchange charomatography, the polysaccharide aqueous solution was separated into two fractions, designated as APS1 and APS2 (Fig. 1A). The primary fraction, APS2, was then collected and purified with Sephadex G-100 charomatography. As a result, two purified fractions were generated, termed APS2-1 and APS2-2 (Fig. 1B). Considering the ease of obtaining APS2-1, the subsequent experiments focused on the APS2-1 fraction.

The UV spectrum of the APS2-1 is shown in Fig. 1C. No peak was observed at $280 \mathrm{~nm}$, suggesting that APS2-1 carried no protein or polypeptide. The FT-IR spectrum of APS2-1 showed the characteristic polysaccharide $\mathrm{OH}\left(3,390 \mathrm{~cm}^{-1}\right)$ and CO stretch $\left(1,010 \mathrm{~cm}^{-1}\right)$, as shown in Fig. 1D (11). The band at 2,930 $\mathrm{cm}^{-1}$ was attributed to asymmetrical stretching vibration of the $\mathrm{CH}_{2}$-group (12). Absorption at $1,640 \mathrm{~cm}^{-1}$ was due to being associated with water. The band at $1,420 \mathrm{~cm}^{-1}$ was assigned to the $\mathrm{C}-\mathrm{OH}$ deformation vibration with the contribution of C-O-C symmetric stretching vibration of the carboxylate group. The band at $\sim 1,160 \mathrm{~cm}^{-1}$ was associated with $\mathrm{C}-\mathrm{O}-\mathrm{C}$ asymmetric stretching vibration in the glycosidic groups of polysaccharides (13). The absorption peak at $914 \mathrm{~cm}^{-1}$ was caused by D-glucopyranose, and the presence of a $\beta$-glycosidic bond was indicated by the band at $\sim 760 \mathrm{~cm}^{-1}$ (14).

Effect of APS2-1 on HSF cell proliferation and migration. Fibroblast proliferation is an important step in wound healing for granulation formation. The proliferation rate affects the wound healing rate. As shown in Fig. 2, APS2-1 concentrations of 1,5 and $25 \mathrm{mg} / 1$ stimulated the proliferation of the HSF cells in a dose-dependent manner, compared with $0 \mathrm{mg} / \mathrm{l}$. As the concentration of APS2-1 increased between 5 and $25 \mathrm{mg} / 1$, it significantly stimulated the proliferation of the HSF cells $(\mathrm{P}<0.01$; Fig. 2A). The difference in proliferation rates between HSF cells treated for 48 and $72 \mathrm{~h}$ with APS2-1 was not significant at a concentration of $25 \mathrm{mg} / \mathrm{ml}(\mathrm{P}>0.05$; Fig. $2 \mathrm{~B})$. Therefore, in the following experiments, the HSF cells treated with $25 \mathrm{mg} / \mathrm{l}$ APS2-1 for $48 \mathrm{~h}$ were used in the cell migration assay.

Effect of $25 \mathrm{mg} / \mathrm{l}$ APS2-1 on HSF cell migration. The effect of ASP2-1 on HSF cell migration was determined, the results of which are shown in Fig. $2 \mathrm{~B}$ and $\mathrm{C}$. The numbers of migrated cells following treatment with $25 \mathrm{mg} / 1$ APS2-1 for 24, 48 and 
A

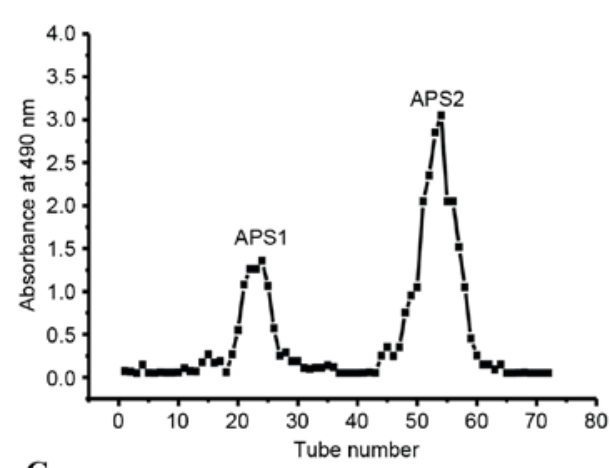

C

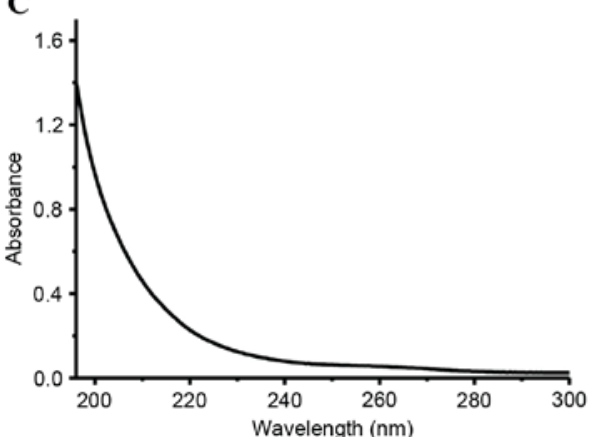

B

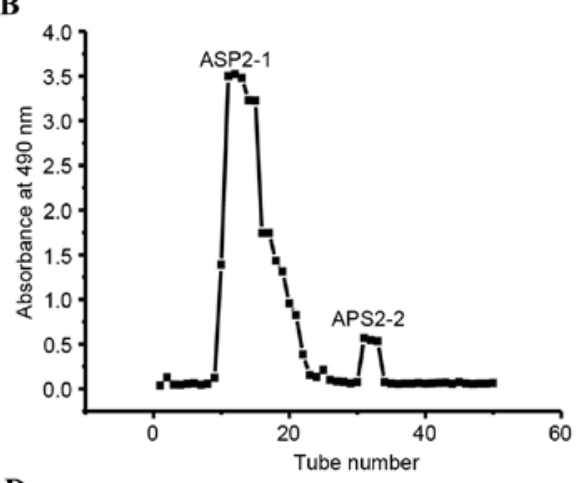

D

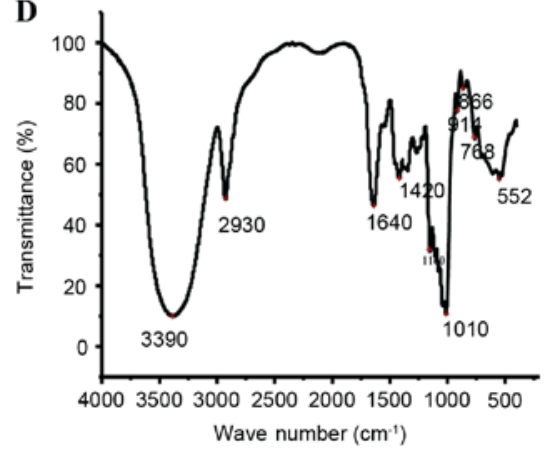

Figure 1. Chromatograms of APS. (A) DEAE-cellulose 52 column; (B) Sephadex G-100 column; (C) UV spectra of APS2-1; (D) FT-IR spectra of APS2-1. APS2-1.

A

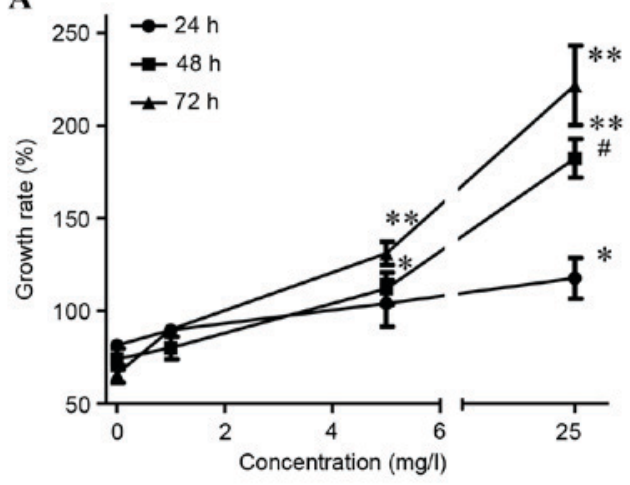

B

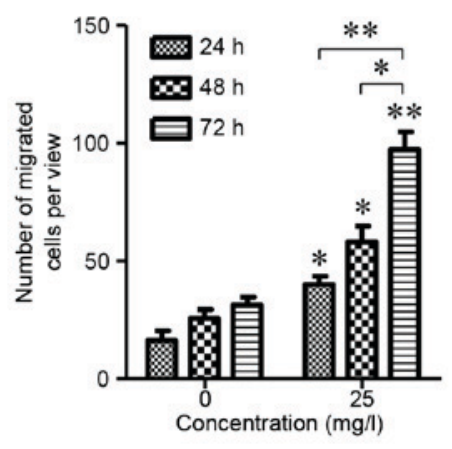

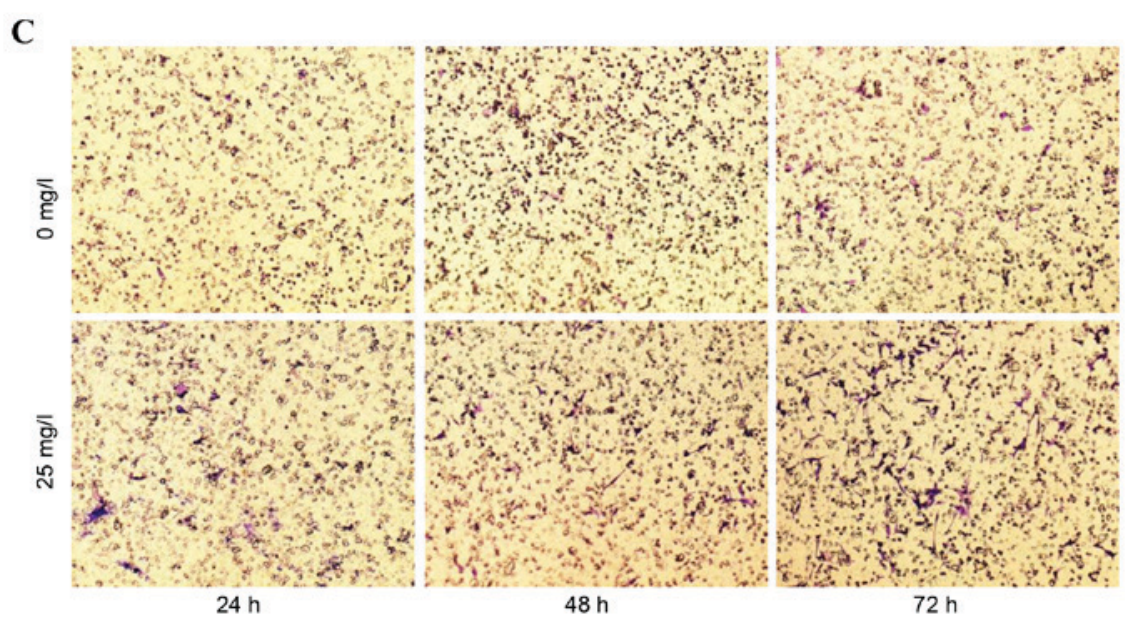

Figure 2. (A) Effects of APS2-1 at different concerations $(0,1,5$ and $25 \mathrm{mg} / \mathrm{l})$ on the proliferation of human fibroblasts. ${ }^{*} \mathrm{P}<0.05$ and ${ }^{* *} \mathrm{P}<0.01$, compared with $0 \mathrm{mg} / \mathrm{ml}$ group; ${ }^{\#} \mathrm{P}<0.05$, compared with $24 \mathrm{~h}$ group at the same concentration. (B) Average numbers of migrated cells per view following treatment with 25 mg/1 APS2-1. (C) Fibroblast morphology (magnification, x100) of migrated cells following treatment with 25 mg/l APS2-1 for 48 and 72 h. 
A

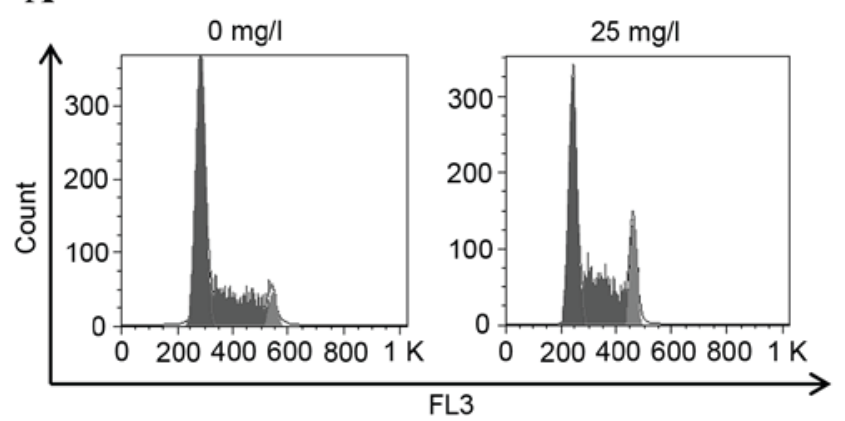

B

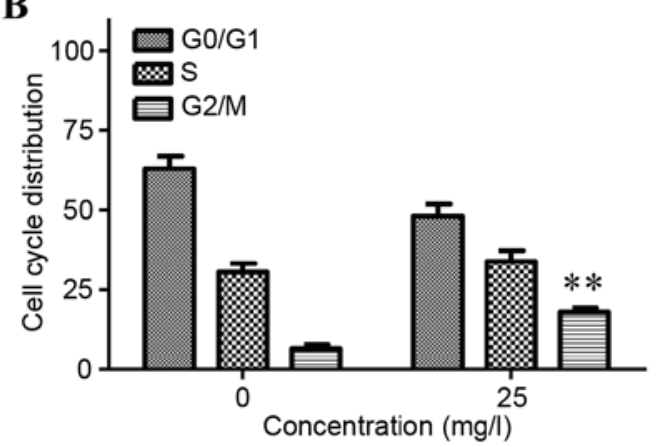

Figure 3. Effect of APS2-1 on HSF cell cycle. (A) HSF cell cycle distribution, detected using flow cytometry. (B) Distribution of the cell cycle. "P<0.05 and ${ }^{* *} \mathrm{P}<0.01$, compared with the control. HSF, human skin fibroblast.

A

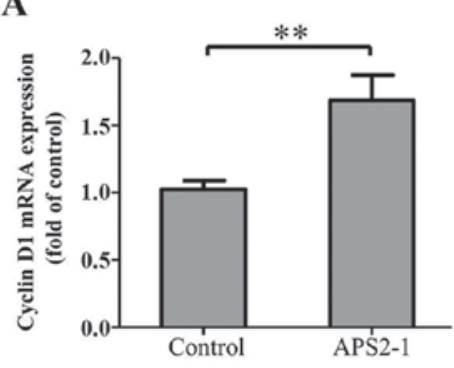

B

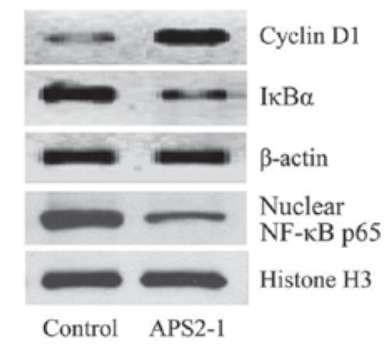

C

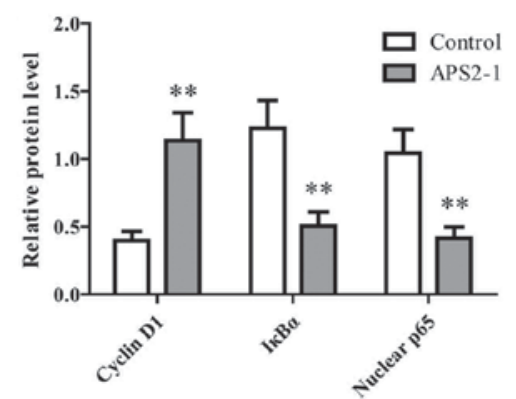

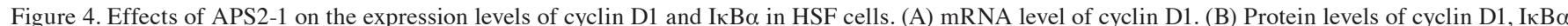

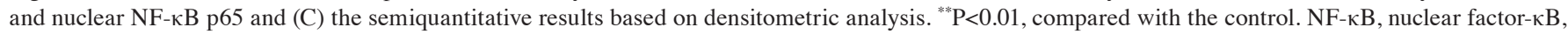

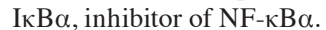

$72 \mathrm{~h}$ were higher, compared with those in the control. As the culture duration increased, the number of migrated cells also increased, and there were significant differences between treatment durations $(\mathrm{P}<0.05$ and $\mathrm{P}<0.01$; Fig. 2B). These results showed that APS2-1 may be a stimulus for HSF cell propagation and migration.

Effect of APS2-1 on cell cycle progression of HSF cells. As shown in Fig. 3A and B, a statistically significant increase was demonstrated in the proportion of cells in the G2/M phase from $5.23 \pm 1.36$ to $16.07 \pm 1.02 \%$ in the $25 \mathrm{mg} / \mathrm{l}$ group $(\mathrm{P}<0.01)$. These results suggested that APS2-1 promoted cell cycle progression by increasing the percentage of cells in the $\mathrm{S}$ and G2/M phases, and decreasing the percentage of cells in the G0/G1 phase, leading to promotion of cell division cycle at the concentration of $25 \mathrm{mg} / \mathrm{l}$.

Effect of APS2-1 on the expression of I $k \alpha \alpha$ and cyclin D1. Cyclin D1, an important cell cycle regulatory factor at the G1 phase, can regulate $\mathrm{E} 2 \mathrm{~F}$ target genes, which assist cells through the G1 phase and in entering the S phase. Downregulated cyclin D1 promotes the transition of G1/S phase in cells, which shortens the G1/S stage and accelerates cell proliferation (15). As shown in Fig. 4A, 25 mg/l APS2-1 significantly increased the mRNA expression of cyclin D1 in the HSF cells, leading to accelerated cell cycle progression and promoting cell proliferation.
Wound formation is coupled with the overproduction of proinflammatory signaling cytokines, including, NF- $\mathrm{KB}$ and $I \kappa B \alpha$, which have important pathological roles in the progression of wound healing (16). NF- $\kappa \mathrm{B}$ remains in an inactive form when combined with inhibitory proteins

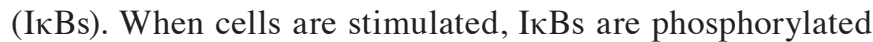
by $\mathrm{I} \kappa \mathrm{B}$ kinase, leading to $\mathrm{I} \kappa \mathrm{B}$ degradation. As shown in Fig. 4B and C, APS2-1 significantly $(\mathrm{P}<0.01)$ decreased the level of phosphorylation of I $\kappa \mathrm{B} \alpha$, and inhibited the translocation of the NF- $\mathrm{B}$ p 65 subunit from the cytoplasm to the nucleus.

Wound healing effect of APS2-1 on the C57BL/6 mice wound model. As shown in Fig. 5A, the APS2-1-treated wound groups exhibited accelerated wound closure, compared with the control group and showed no significant difference, compared with the positive group. This enhancement appearance was observed at 7 days post-surgery, and became more evident on day 14. At 21 days, complete wound closure was observed in the APS2-1 treated mice, whereas no completion occurred in the control groups (Fig. 5A). In order to further examine the difference between the three groups, histopathological examination was performed to determine the wound tissue at 14 days. As shown in Fig. 5B, mass inflammatory cell infiltration was observed in the control group. In the APS2-1-treated mice, the infiltration was reduced and fibroblasts appeared (Fig. 5B). In addition, new blood vessels and skin appeared in 
A

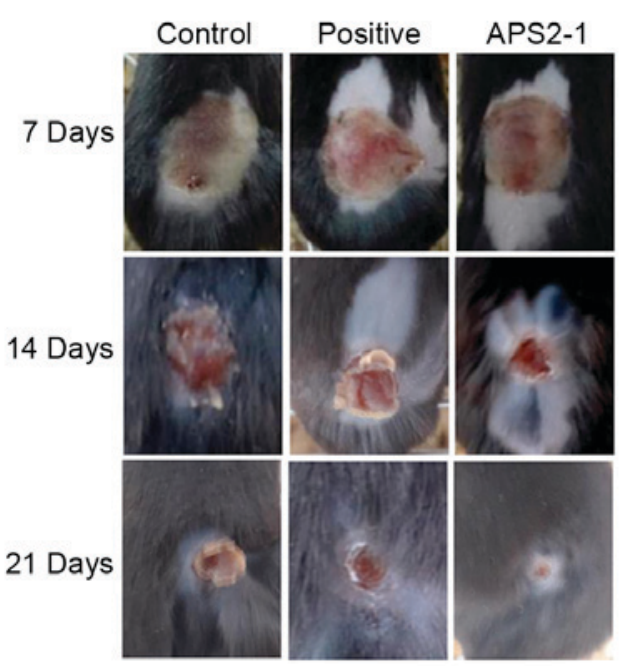

B

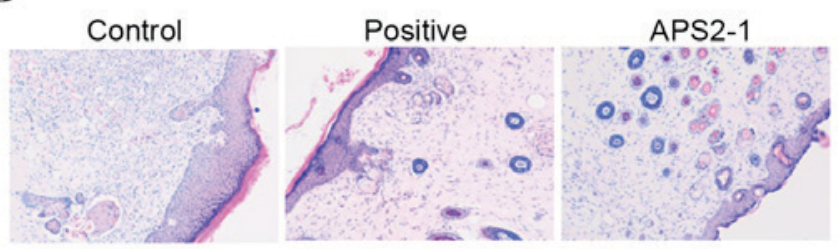

Figure 5. Wound healing effect of APS2-1 in a mouse wound model. (A) Images of wound closure at 7, 14 and 21 days among the three groups. (B) Hematoxylin and eosin staining of repaired skin at 14 days (magnification, $\mathrm{x} 100$ ).

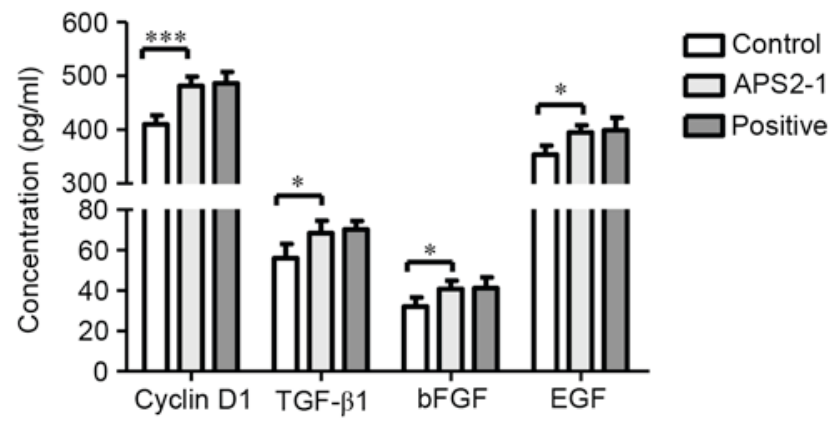

Figure 6. Effects of APS2-1 on levels of cyclin D1, TGF- $\beta 1$, bFGF and EGF in scalded tissue at 7 days. ${ }^{*} \mathrm{P}<0.05$ and ${ }^{* * *} \mathrm{P}<0.001$, compared with the control. TGF- $\beta 1$, transforming growth factor- $\beta 1$; bFGF, basic fibroblast factor; EGF, epidermal growth factor.

the APS2-1 and positive groups, suggesting that APS2-1 was capable of healing wounds by promoting re-epithelialization and revascularization.

Effect of APS2-1 on levels of cyclin D1,TGF- $\beta 1, b F G F$ and $E G F$. Fibroblasts, an important type of stromal cell, appear in the process of wound healing and secrete numerous cytokines, including TGF- $\beta 1, \mathrm{bFGF}, \mathrm{EGF}$ and insulin-like growth factor 1. TGF- $\beta 1$ is also important in wound repair, which can promote fibroblast proliferation and the secretion of extracellular matrix, and inhibit its degradation (17). As shown in Fig. 6, the levels of cyclin D1 and TGF- $\beta 1$ in the APS2-1-treated mice were significantly higher $(\mathrm{P}<0.001$ for cyclin $\mathrm{D} 1$, and $\mathrm{P}<0.05$ for TGF- $\beta 1$ ), compared with those in the control mice, and no significant difference $(\mathrm{P}>0.05)$ was found between the APS2-1 and positive groups.

EGF and bFGF are important stimulators in the formation of re-epithelialization and keratinocyte migration in wound healing. During the first 7 days post-wounding, the wounds treated with APS2-1 had significantly increased EGF and bFGF, compared with those in the control group $(\mathrm{P}<0.05$; Fig. 6).

TGF- $\beta 1$ is a member of the TGF- $\beta$ family, which is closely associated with anti-inflammatory effects, the regulation of differentiation, chemostasis to macrophages and the control of matrix synthesis in wound repair (18). As shown in Fig. 6, TGF- $\beta 1$ was significantly increased in the APS2-1-treated mice, compared with the mice in the control group.

\section{Discussion}

Wound healing is a complex and ordered sequence of events, which involves cell migration, proliferation, inflammation, synthesis of extracellular matrix and wound remodeling (19). Generally, wound healing rate, wound healing duration and pathological analysis of skin wounds are direct and effective evaluation indices of wound healing effects (20). The ordered sequence of wound healing involves cell proliferation and migration, synthesis of extracellular matrix, angiogenesis and remodeling (7).

When a wound occurs, there are several types of cells recruited for involvement in the healing process (21). For example, neutrophils, monocytes and mast cells infiltrate the site of injury and produce cytokines (22). Fibroblasts, endothelial cells and keratinocytes then proliferate and migrate due to the released cytokines stimulated. Fibroblasts, one of the most common connective tissue cells, are critical in wound healing. During wound healing, fibroblasts interact with surrounding cells, including fat cells, mast cells and keratinocytes, but also produce extracellular matrix, glycoprotein, adhesive molecules and various cytokines. Through cell-to-cell direct contact, and cell-to-cytokine indirect contact, fibroblasts contribute to repair wounds.

In addition, fibroblasts in wound edges begin to grow and migrate into the provisional matrix of the wound to form granulation tissue $(7,21,23)$. The roles of the exogenous growth factors associated with wound repair have been demonstrated to vary, and include bFGF, EGF, TGF- $\alpha$ and TGF- $\beta(21,24,25)$. Zhang et al (7) reported that a type of traditional Chinese medicine exertes wound-healing effects on the Hs27 human skin fibroblast cell line via activation of the TGF- $\beta 1$ pathway. In addition, Telgenhoff and Shroot (26) reported that chronic wound fluid rapidly degrades exogenous growth factors and decreases the production of cyclin D1. Thus, the evaluation of the expression of cyclin D1 is also required for further investigation of the wound healing properties of active components.

In the present study, the APS2-1 fraction was purified from a type of commercial Astragali. It was then demonstrated that APS2-1 inhibited the expression of I $\mathrm{B} \alpha$ and cyclin D1 of HSF cells, and promoted the proliferation, migration and cycle progression of the HSF cells. On further investigation, in vitro experiments revealed the mRNA and protein expression levels of I $\mathrm{B} \alpha$ and cyclin D1 also decreased in the presence of APS2-1. 
APS2-1 was capable of promoting the re-epithelialization, revascularization and cytokine secretion of TGF- $\beta 1$, bFGF and EGF. Ultimately, the mechanism underlying the wound healing properties of APS2-1 may be associated with reducing the inflammatory response, promoting cell cycle progression and the secretion of cytokines.

\section{References}

1. Yao $\mathrm{X}, \mathrm{Wu} \mathrm{G}$ and $\mathrm{Yu} \mathrm{WM}$ : The effect of huangqi injection on immune function in rats with scald. Chin Tradit Pat Med 7: 494-496, 2000.

2. Yi Z, Zhang M, Shi S and Wang S: Effects of astragalus extract combined with rhEGF on scalded wound healing and vascularization in rats. China Pharmacist 1: 9-12, 2012 (In Chinese).

3. Yang Y, Wang F, Yin D, Fang Z and Huang L: Astragulus polysaccharide-loaded fibrous mats promote the restoration of microcirculation in/around skin wounds to accelerate wound healing in a diabetic rat model. Colloids and surfaces B Biointerfaces 136: 111-118, 2015.

4. Cui J, Gu X, Wang F, Ouyang J and Wang J: Purification and structural characterization of an $\alpha$-glucosidase inhibitory polysaccharide from apricot (Armeniaca sibirica L. Lam.) pulp. Carbohyd Polym 121: 309-314, 2015.

5. Staub A: Removal of protein-Sevag method. Meth Carbohyd Chem 5: 5-6, 1965.

6. Lau KM, Lai KK, Liu CL, Tam JC, To MH, Kwok HF, Lau CP, Ko CH, Leung PC, Fung KP, et al: Synergistic interaction between Astragali Radix and Rehmanniae Radix in a Chinese herbal formula to promote diabetic wound healing. J Ethnopharmacol 141: 250-256, 2012.

7. Zhang Q, Fong CC, Yu WK, Chen Y, Wei F, Koon CM, Lau KM, Leung PC, Lau CB, Fung KP and Yang M: Herbal formula Astragali Radix and Rehmanniae Radix exerted wound healing effect on human skin fibroblast cell line Hs27 via the activation of transformation growth factor (TGF-beta) pathway and promoting extracellular matrix (ECM) deposition. Phytomedicine 20: 9-16, 2012.

8. Gu M, Xu J, Han C, Kang Y, Liu T, He Y, Huang Y and Liu C: Effects of berberine on cell cycle, DNA, reactive oxygen species and apoptosis in L929 murine fibroblast cells. Evid Based Complement Alternat Med 2015: 796306, 2015.

9. Livak KJ and Schmittgen TD: Analysis of relative gene expression data using real-time quantitative PCR and the 2(-Delta Delta C(T)) Method. Methods 25: 402-408, 2001.

10. Liu X, Wang Z, Wang R, Zhao F, Shi P, Jiang Y and Pang X: Direct comparison of the potency of human mesenchymal stem cells derived from amnion tissue, bone marrow and adipose tissue at inducing dermal fibroblast responses to cutaneous wounds. Int J Mol Med 31: 407-415, 2013.

11. O'Connor NA, Abugharbieh A, Yasmeen F, Buabeng E, Mathew S, Samaroo D and Cheng HP: The crosslinking of polysaccharides with polyamines and dextran-polyallylamine antibacterial hydrogels. Int J Biol Macromol 72: 88-93, 2015.
12. Zhang S, He B, Ge J, Li H, Luo X, Zhang H, Li Y, Zhai C, Liu P, Liu X and Fei X: Extraction, chemical analysis of Angelica sinensis polysaccharides and antioxidant activity of the polysaccharides in ischemia-reperfusion rats. Int J Biol Macromol 47: 546-550, 2010.

13. Sadat Hosseini M, Hemmati K and Ghaemy M: Synthesis of nanohydrogels based on tragacanth gum biopolymer and investigation of swelling and drug delivery. Int J Biol Macromol 82: 806-815, 2016.

14. Xu JK, Li MF and Sun RC: Identifying the impact of ultrasound-assisted extraction on polysaccharides and natural antioxidants from Eucommia ulmoides Oliver. Process Biochem 50: 473-481, 2015.

15. Coller HA: What's taking so long? S-phase entry from quiescence versus proliferation. Nat Rev Mol Cell Biol 8: 667-670, 2007.

16. Thomasova D, Mulay SR, Bruns H and Anders HJ: p53-independent roles of MDM2 in NF- $\kappa$ B signaling: Implications for cancer therapy, wound healing, and autoimmune diseases. Neoplasia 14: 1097-1101, 2012

17. Thorey IS, Hinz B, Hoeflich A, Kaesler S, Bugnon P, Elmlinger M, Wanke R, Wolf E and Werner S: Transgenic mice reveal novel activities of growth hormone in wound repair, angiogenesis, and myofibroblast differentiation. J Biol Chem 279: 26674-26684, 2004.

18. Barrientos S, Stojadinovic O, Golinko MS, Brem H and Tomic-Canic M: Growth factors and cytokines in wound healing. Wound Repair Regen 16: 585-601, 2008.

19. Peppa M, Stavroulakis P and Raptis SA: Advanced glycoxidation products and impaired diabetic wound healing. Wound Repair Regen 17: 461-472, 2009.

20. Ali A, Herndon DN, Mamachen A, Hasan S, Andersen CR, Grogans RJ, Brewer JL, Lee JO, Heffernan J, Suman OE and Finnerty CC: Propranolol attenuates hemorrhage and accelerates wound healing in severely burned adults. Crit Care 19: 217, 2015.

21. Werner S and Grose R: Regulation of wound healing by growth factors and cytokines. Physiol Rev 83: 835-870, 2003.

22. Trautmann A, Toksoy A, Engelhardt E, Brocker EB and Gillitzer R: Mast cell involvement in normal human skin wound healing: Expression of monocyte chemoattractant protein-1 is correlated with recruitment of mast cells which synthesize interleukin-4 in vivo. J Pathol 190: 100-106, 2000.

23. Farmer DR and Nelson DM: A fibrin matrix modulates the proliferation, hormone secretion and morphologic differentiation of cultured human placental trophoblast. Placenta 13: 163-177, 1992.

24. Guo S and Dipietro LA: Factors affecting wound healing. J Dent Res 89: 219-229, 2010.

25. Schlingemann RO: Role of growth factors and the wound healing response in age-related macular degeneration. Graefes Arch Clin Exp Ophthalmol 242: 91-101, 2004.

26. Telgenhoff D and Shroot B: Cellular senescence mechanisms in chronic wound healing. Cell Death Differ 12: 695-698, 2005. 